\title{
MR and CT imaging of Arrhythmogenic Cardiomyopathy
}

\author{
Harikrishna Tandri, MD and Hugh Calkins, MD \\ Division of Cardiology, The Johns Hopkins University, Baltimore, MD
}

\begin{abstract}
Right ventricular structure and functional alterations are important criteria for the diagnosis of arrhythmogenic cardiomyopathy (AC). As such, accurate and reliable evaluation of RV is desirable both for establishing the diagnosis and for follow up evaluation of AC. Right ventricle has a unique three dimensional geometry and complex contraction pattern ${ }^{1}$. Thus conventional non invasive imaging modalities like the echocardiography and radio nuclide ventriculography are limited in their assessment. Recently Magnetic resonance (MR) imaging and computed tomography (CT) have emerged as robust tools to evaluate the RV in patients with suspected $\mathrm{AC}^{2-6}$. The noninvasive nature of these investigations, multiplanar capability, and unique ability to provide tissue characterization are ideal for assessment of AC. Both modalities have the ability to provide direct evidence of fatty infiltration and structural alterations of the RV The purpose of the current chapter is to discuss the current status, strengths and limitations of MR imaging and cardiac CT, in evaluation of AC.
\end{abstract}

\section{MR Imaging in Arrhythmogenic Cardiomyopathy}

Over the last decade there have been significant improvements in MR imaging hard ware such as dedicated cardiac coils, faster imaging, and excellent blood pool contrast with steady state free precession imaging, which has made MR imaging the imaging modality of choice for cardiac applications. ECG gating and breath-hold imaging have reduced motion artifacts and improved tissue contrast is achieved by inversion recovery black-blood imaging techniques ${ }^{7}$. Steady state free precession imaging (SSFP) pulse sequence, have resulted in better delineation of endocardial borders, enabling accurate and reproducible volumetric measurements ${ }^{8}$. MR imaging is now routinely used for quantitative and qualitative assessment of cardiac function. Among the current cardiac MR imaging applications in cardiomyopathies, the greatest potential as well as biggest challenges are in the diagnosis of AC. Routinely used imaging planes are sub-optimal for RV evaluation and the technique of $\mathrm{AC}$ imaging involves unconventional imaging planes. Furthermore the lack of familiarity of the MR readers with the RV contraction pattern and the normal epicardial fat distribution poses challenges for accurate and reproducible reporting.

Despite the above limitations, MR imaging is uniquely suited for evaluation of AC. It has the ability to non-invasively provide tissue characterization for detection of fat infiltration and fibrosis in the RV, which are the histopathologic hall marks of $\mathrm{AC}^{9-11}$. Quantitative and reproducible data on $\mathrm{RV}$ volumes and function are not only useful in establishing the diagnosis, but also for follow-up of AC patients. Finally, the multiplanar depiction of RV

\footnotetext{
(c) 2011 Elsevier Inc. All rights reserved.

Address For Correspondence: Harikrishna Tandri, M.D., Carnegie 565 D, The Johns Hopkins Hospital, 600, N Wolfe Street, Baltimore MD 21287, Phone: (410) 502-7861 (office), Fax: (410) 502-9148, htandri1 @jhmi.edu, www.arvd.com.

Publisher's Disclaimer: This is a PDF file of an unedited manuscript that has been accepted for publication. As a service to our customers we are providing this early version of the manuscript. The manuscript will undergo copyediting, typesetting, and review of the resulting proof before it is published in its final citable form. Please note that during the production process errors may be discovered which could affect the content, and all legal disclaimers that apply to the journal pertain.
} 
wall motion is invaluable in assessing RV regional contraction abnormalities, which are often the earliest manifestation of AC.

\section{MR imaging protocol}

The MR imaging protocol in right ventricular dysplasia is aimed at recognizing two important aspects of the disease process: (a) fibro-fatty infiltration of the right ventricle, (b) global and regional right ventricular dysfunction. Hence the protocol includes (a) blackblood imaging to identify intramyocardial fatty infiltration, (b) bright-blood cine imaging to visualize right ventricular global and regional dysfunction and (c) myocardial delayed enhancement images. Table 1 shows the MR imaging protocol used at our center. Typically axial and short axis black blood images are acquired for detecting fat infiltration. Axial, short axis and four chamber images are acquired for assessing RV and left ventricle (LV) wall motion. Delayed enhanced images are obtained in the same views as the functional images. For black-blood techniques breath-hold imaging with double inversion recovery fast spin echo (FSE) techniques are preferred to traditional spin echo (SE) imaging. These techniques substantially shorten the imaging time and are devoid of respiratory motion artifacts. Black blood inversion prepared half-Fourier single-shot turbo spin echo (HASTE) imaging has not been systematically evaluated, but is currently not recommended due to blurring of detail with this sequence. For bright-blood imaging steady state free precession imaging is the most preferred technique (FIESTA, true FISP, Balanced Fast Field Echo). If those cine sequences are not available, segmented k-space cine gradient echo images (e.g.; fast low angle shot-FLASH; fast cardiac gated gradient echo-FASTCARD) can be used. All images are optimally performed during end expiratory breath-hold. Delayed enhanced images are obtained at our center using $2 \mathrm{D}$ inversion recovery prepped gradient echo imaging or Phase Selective Inversion Recovery (PSIR) sequences. It is important to use a dedicated cardiac coil for imaging and to use the anterior coil alone while obtaining the black blood images. The later prevents wrap around artifacts. Also not infrequently these patients present with frequent ventricular premature beats that cause blurring of the image due to inadequate gating. If the patient is known to have frequent ventricular ectopy, we recommend the use of oral Metoprolol $50 \mathrm{mg}$, at least 1 hour prior to the procedure provided that the patient has no contraindications. If ventricular arrhythmias are frequent then the resulting scan quality will be poor and the test becomes uninterpretable.

\section{MR imaging findings in Arrhythmogenic Cardiomyopathy}

Broadly, MR imaging abnormalities in AC can be grouped into two major categories: 1) morphological abnormalities, and 2) functional abnormalities. Morphologic abnormalities include intramyocardial fat deposits, focal fibrosis, wall thinning, wall hypertrophy, trabecular disarray, and RV outflow tract enlargement. Functional abnormalities include regional contraction abnormalities, aneurysms, RV global dilation /dysfunction, and RV diastolic dysfunction. The sites of involvement of these abnormalities are observed in the "triangle of dysplasia", which is constituted by the inferior-sub tricuspid area, RV apex and the RV infundibulum (Figure 2). The goal of MR imaging in AC is to accurately assess the $\mathrm{RV}$ for the presence or absence of these abnormalities, to aid in the diagnosis and follow-up of patients.

\section{Intramyocardial fat}

Abundant epicardial and intrapericardial fat is commonly found over the RV but intramyocardial fat infiltration in the right ventricle is rare. A clear line of demarcation exists between the epicardial fat and the RV myocardium in normal subjects Figure $3 a$ \& b) and a disruption of this line is often seen in patients with AC. Shown in Figure 4 is a classic 
example of fat infiltration in AC. Note the finger like projections of the epicardial fat (4a) causing a signal void in the myocardium in the fat-suppressed images (figure $4 \mathrm{~b}$ ).

The prevalence of intramyocardial fat in $\mathrm{AC}$ on $\mathrm{T} 1$ weighted SE imaging has ranged from $22 \%$ to $100 \%$ in different studies $2,10,12-14$. We used breath-hold double inversion recovery fast spin echo technique to evaluate intramyocardial fat in AC, and found a high intramyocardial $\mathrm{T} 1$ signal (fat) in 9 of 12 patients (75\%) who were prospectively diagnosed using the current Task Force criteria ${ }^{10}$. The differences in incidence of fat signal among various studies in $\mathrm{AC}$ are largely based on differences in patient selection, different imaging techniques used and most importantly on the definition of abnormal intramyocardial fat. It is known from the autopsy studies that the degree of fat infiltration is associated with the stage of the disease. Advanced AC is often associated with greater degree of fat infiltration and there may be no evidence of macroscopic fat infiltration on imaging in the early stages of the disease ${ }^{15}$. Current MR imaging resolution however is insufficient to diagnose early stages of the disease, even when there is clear evidence of fat infiltration on histopathology.

Fat infiltration when present is predominantly seen in the RV outflow tract and the anterior RV free wall and the basal RV especially close to the RV inlet. Shown in Figure 4 is the classic appearance of fat infiltration in AC. Note the disruption of the border between the epicardial fat and the RV wall. Fat suppressed image shows multiple signal voids within the $\mathrm{RV}$ myocardium. Detection of fat infiltration close to the apex however is challenging as this region is usually very thin $(2 \mathrm{~mm}-4 \mathrm{~mm})$ and there is abundant fat close to the cardiac apex. In any case, the use of spectrally selective fat suppression with the black blood sequences provides additional evidence of fat infiltration due to high contrast between epicardial fat and the RV myocardium. The accurate delineation of the underlying RV free wall increases the confidence of diagnosis for the MR physician.

Although detection of fat infiltration on MR imaging is moderately sensitive to the disease process, the specificity of this finding is unclear. Detection of intramyocardial fat on MR imaging requires considerable experience and over reliance on this finding alone often leads to mis-diagnosis of AC. Excessive epicardial fat can often masquerade as fat replacement of the RV (Figure 5a \& b)). In some cases this will also distort RV regional wall motion further confusing the issue. Steroid use, alcoholism, obesity and old age have all been associated with fat infiltration ${ }^{16-18}$. Nevertheless the classic appearance of segmental fat infiltration appears to be unique to AC. However, it cannot be underscored that reliable interpretation of this finding requires considerable expertise, which is often difficult to establish in this rare disease.

\section{Wall Thinning and Wall hypertrophy}

$\mathrm{RV}$ wall thinning is defined focal abrupt reduction in wall thickness to $<2 \mathrm{~mm}$, surrounded by regions of normal wall thickness. This finding is uncommon in AC and is often overcalled especially close to the RV apex where the RV tends to be normally very thin. Wall thinning is due to progressive loss of epicardial and myocardial layers that leaves a thin rim of endocardial cells, which are usually not involved until late in the disease process. In our series we found wall thinning in less than $25 \%$ of patients who met the Task Force criteria. In our experience wall thickness is often difficult to assess due to adjacent high epicardial fat signal and motion artifacts.

Wall hypertrophy, defined as RV wall thickness $>8 \mathrm{~mm}$ is usually an MR appearance wherein it is impossible to differentiate the true RV wall from the overlying epicardial fat as the line of separation is completely disrupted. This finding is seldom observed in pathologic specimens as the true RV myocardium is measured exclusive of the epicardial fat ${ }^{19}$. In vivo this differentiation is sometimes not possible due to extensive fibro-fatty infiltration with 
loss of distinction between epicardial fat and the true myocardium. In such cases the RV wall appears hypertrophied with MR images showing islands of grey muscle surrounded by bright signals compatible with fat. Fat suppressed image reveals multiple signal voids within the RV myocardium in locations that showed hyperintense signals in the non-fat suppressed images (Figure 4b).

\section{Trabecular Disarray}

Heavy trabeculation of the RV is frequently observed in $\mathrm{AC}$, more so in patients with RV dysfunction. Hypertrophy of the trabeculae and the RV endocardium which compensate for the epicardial myocyte loss is thought to result in this apperance. Occasionally giant $Y$ shaped trabeculae and hypertrophy of the moderator band are observed in patients with AC. This finding has been equated to the angiographic finding of deep fissures with a "pile d'assiettes' (stack of plates) appearance. RV trabecular disarray is a finding that is not specific for AC and may be present in any condition that results in RV hypertrophy or enlargement.

\section{RV Outflow Tract Enlargement}

In our experience the RV outflow tract (RVOT) is the most common location for localized AC. The right ventricular outflow is usually equal to or marginally smaller than the aortic outflow tract at the level of the aortic valve. An exception to this rule is pediatric patients in whom the RVOT may be larger than the left ventricular outflow. Presence of an enlarged RVOT beyond adolescence is uncommon. More important than a simple enlargement is a dysmorphic appearance of the outflow tract (Figure 6). Abnormal appearance of the RVOT, which is dyskinetic in systole, is highly suggestive of $\mathrm{AC}$ in the absence of pulmonary hypertension.

\section{MR imaging fibrosis in Arrhythmogenic Cardiomyopathy}

One of the pathologic hallmarks of $\mathrm{AC}$ is fibrosis of the RV that accompanies fatty infiltration. Myocardial delayed enhancement MR imaging allows for non-invasive detection of fibrosis in the RV. Delayed enhancement detected by MR imaging shows excellent correlation with histopathology and an inverse correlation with global RV function ${ }^{20}$. Further, areas of delayed enhancement often show wall motion abnormalities on cine imaging. Common sites for delayed enhancement are the basal sub-tricuspid region, the acute angle of the right ventricle and the RV outflow tract (Figure 7). Presence of delayed enhancement also predicts inducibility of re-entrant ventricular tachycardia in AC. One of the most important uses of delayed enhancement imaging is its role in differential diagnosis. Presence extensive bi-ventricular delayed enhancement in a patient being evaluated for AC should suggest alternative diagnoses such as sarcoidosis or myocarditis. The myocardium of the interventricular septum is rarely involved in $\mathrm{AC}$ and frequently involved in sarcoidosis (Figure 8). The differentiation of isolated RV myocarditis and sarcoidosis involving the RV from $\mathrm{AC}$ is often difficult using MR imaging alone. Both sarcoidosis and myocarditis can show patchy involvement of the LV and fat infiltration is strikingly absent. Clinical findings such as conduction disease, multisystem involvement and hilar lymphadenopathy suggest sarcoidosis even when the MR imaging findings are indistinguishable.

\section{Left Ventricular Involvement in Arrhythmogenic Cardiomyopathy}

Desmosomal mutations affect both ventricles; hence it has been argued that AC is a biventricular disease with predominant involvement of the right ventricle. Studies to date suggest that LV involvement may be dependent on the underlying mutation. Mutations in Desmoplakin and Plakoglobin have been associated with bi-ventricular AC or in some cases 
left dominant $\mathrm{AC}^{21}$. Mutations in plakophillin-2 (PKP2) on the other hand result in the classic form of $\mathrm{AC}$ with minimal LV involvement, at least minimal global functional involvement ${ }^{22}$. Histologic studies however have reported LV involvement in up to $70 \%$ of patients, but these are typically autopsy data and the extent of disease is unknown.

Left ventricular MR imaging findings in AC are unique and are mostly localized to the basal inferior and infero-lateral left ventricle (Figure 9). This is typically in the form of fat infiltration that extends from the epicardium in to the myocardium with sparing of the endocardium. Fat infiltration in this location is not seen in any other disease, thus making this a finding that is unique to AC. Even with extensive amount of fat, global LV function is not affected possibly because this is localized and well compensated by the remainder of the LV. The same site may show delayed enhancement, however, this may be difficult to reconcile from fat infiltration unless a fat suppressed delayed enhanced sequence is performed. Severe LV dysfunction and LV arrhythmias are rare in PKP2 related AC.

\section{MR Assessment of Cardiac Function in Arrhythmogenic Cardiomyopathy}

The techniques to image cardiac function are called "bright-blood" techniques, derived from the appearance of intracavitary blood. Consecutive images that are acquired with a high temporal resolution can be viewed dynamically to generate functional information. Although a number of sequences exist for bright-blood imaging, steady state free precession imaging is the most preferred technique (FIESTA, true FISP, Balanced Fast Field Echo). SSFP sequences result in improved contrast between the blood pool and the myocardium compared to segmented $k$-space cine gradient echo images. If SSFP is not available, segmented $k$-space cine gradient echo images (e.g.; fast low angle shot—FLASH; fast cardiac gated gradient echo-FASTCARD) can be used. Conventional gradient recalled (GRE) imaging sequences rely on flowing blood to generate bright blood. In the dysfunctional RV, blood velocities are reduced and signal intensity decreases with conventional GRE imaging. With SSFP the signal intensity remains high since the signal intensity is proportional to $\mathrm{T} 2$ time.

Ventricular volumes and mass using bright-blood imaging have been shown to be accurate and reproducible and MR imaging is considered the standard of reference ${ }^{23,24}$.Thus MR imaging is ideal for non invasive assessment global RV functional in patients with suspected $\mathrm{AC}$ and their first degree relatives.

\section{Functional Abnormalities in Arrhythmogenic Cardiomyopathy Global RV dilation/dysfunction}

Fibro-fatty replacement of the RV in AC eventually leads to RV dilation and dysfunction. Moderate to severe RV dysfunction constitutes one of the major task force criteria for AC. Recent refinements to the task force criteria have resulted in introduction of quantitative cutoffs for global RV volumes and function for the diagnosis of $\mathrm{AC}^{25,26}$. $\mathrm{RV}$ dysfunction is often present in the majority patients who meet the task force criteria especially in the absence of a family history of AC. Also there is a linear correlation between the RV end diastolic volumes and the duration of symptoms suggesting the progressive nature of the disease. However, asymptomatic first degree relatives who are diagnosed solely by virtue of their family history or due to presence of a pathogenic mutation often tend to have preserved $R V$ function. Serial quantitative volumetric assessment of RV may play an important in assessing RV function in first-degree relatives. 


\section{Regional Dysfunction}

MR imaging has replaced RV angiography in RV regional function assessment as the former technique is non-invasive and is devoid of ionizing radiation. Regional RV dysfunction is generally thought to be due to focal fibro-fatty infiltration, which precedes changes in global ventricular function. As such, regional dysfunction is seen in the same areas as the fat infiltration; the RVOT, the anterior RV and the basal RV inlet. Shown in Figure 10 is a basal aneurysm in a patient with advanced AC. Regional functional abnormalities of the RV described in AC include focal hypokinesis (wall thickening of $<40 \%$ ), akinesis (systolic wall thickening of $<10 \%$ ), dyskinesis (myocardial segment, which moves outward in systole) and aneurysms (segments with persistent bulging in diastole, and dyskinetic in systole). Studies have consistently reported high incidence of regional dysfunction in AC. The areas of dysfunction corresponded to the areas of signal abnormality observed on black blood MR imaging. The presence of signal abnormality associated with abnormal wall motion is more suggestive of AC compared to either of them alone. In our series, $67 \%$ of the patients had regional contraction abnormalities, which correlated to the area of adipose replacement on MR imaging ${ }^{10}$. RV aneurysmal dilation is often seen in advanced $\mathrm{AC}$ and coexists with global RV dysfunction. Care should be taken while interpreting RV regional function from axial views, as the axial plane is not orthogonal to the inherent axis of the heart and systolic bulging can be seen even in normal volunteers. Correlation with horizontal long axis view may be helpful to avoid misinterpretation of RV regional function.

\section{Genotype-Phenotype correlation}

Genotype-phenotype correlations suggest that PKP2 mutation usually present with the classic, right-dominant disease ${ }^{27}$, while other series with a relatively higher prevalence of desmoplakin mutations consist of patients who show a more diverse phenotype, including the so-called left dominant $\mathrm{AC}^{21}$. Further, the presence of the mutation is associated with higher prevalence of LV fat infiltration compared with AC patients in whom no mutation is found. In mutation positive first degree relatives we have observed minor contraction abnormalities limited to the RV outflow tract and the RV basal region ${ }^{27}$. These regional contraction abnormalities are best described as a focal crinkle in the RV during systole resembling an "Accordion"(Figure 11). Although these findings may be sensitive, they come at a price of reduced specificity and poor reproducibility limiting their use in the diagnosis of AC. Finally, preliminary genotype-phenotype data suggest that disease severity is greater in double mutations carriers, further emphasising the need to screen all known diseasecausing genes even after isolation of a pathogenic mutation.

\section{Role of MR Imaging in Diagnosis of Arrhythmogenic Cardiomyopathy}

Diagnosis of $\mathrm{AC}$ is challenging especially in early stages of the disease. The lack of diagnostic gold standard makes it difficult to define the sensitivity and specificity any single modality in diagnosing AC. Benign arrhythmias arising from the RV outflow tract are frequently encountered in clinical practice and the presence of characteristic structural abnormalities differentiates AC from the benign idiopathic ventricular tachycardia ${ }^{28}$. As such the role of MR imaging in accurate phenotyping is invaluable. However, qualitative findings such as intramyocardial fat infiltration and subtle wall motion abnormalities need considerable expertise for interpretation. Isolated areas of fat replacement are not specific to $\mathrm{AC}$ and have been reported in elderly patients, patients receiving long-term steroids, and in other cardiomyopathies. Recently we have observed marked lipomatous infiltration of the right ventricle in young non-obese individuals who were evaluated for non-sustained ventricular arrhythmias ${ }^{18}$ (Figure 8). None of these patients had global or regional functional abnormalities and thus appeared to be a distinct group of patients defined by MR imaging that should be differentiated from patients with AC. Over-reliance on the presence 
of intramyocardial fat has in fact resulted in a high frequency of "misdiagnosis" of $\mathrm{AC}^{29}$. In our experience this finding alone is neither sensitive nor specific for the diagnosis. Our experience with MR imaging of autopsy hearts lead us to conclude that the achievable spatial resolution in current state-of-the-art clinical protocols substantially limits the capability to detect subtle RV intramyocardial fatty changes. Since the disease is so rare, most imaging centers have little or no experience with diagnosis of AC. Technical problems in imaging patients with arrhythmias, lack of a standardized protocol for AC, and lack of experience by imaging physicians suggest that MRI should be only one part of a comprehensive evaluation for these patients. According to the task force criteria, MR imaging provides information related to RV size, global and regional function and aneurysm formation. Quantitative cut-offs are now a part of the task force criteria and relying on quantitative evaluation of RV size and function is advisable and avoids the risk of over diagnosis of AC.

One of the most important roles of MR imaging is to reliably identify patients who require additional invasive testing. A completely normal MR study in a patient with no abnormalities on electrocardiography or echocardiography is reassuring, and such patients may not need invasive testing (angiography/biopsy) in the absence of other clinical criteria. If signal abnormalities and wall motion abnormalities coexist, invasive testing should be undertaken to confirm the findings. Minor structural abnormalities i.e. signal abnormalities in the absence of wall motion changes presents a challenge as further evaluation of such patients is unclear. Adherence to Task Force criteria is recommended, and these "minor" criteria may not necessitate invasive testing. Further, it must be recognized that AC Task Force criteria do not currently recognize fat signal on MR (or CT) as a diagnostic criterion for the disease.

Finally, when evaluating RV structure special attention should be paid to the RV inflow, RV apex and the outflow tract, as these are the commonly involved sites in AC. We recommend assessing RV function from the axial bright blood cine images. The RV on axial images starts off as a large triangle in diastole, which becomes a smaller triangle in systole. Most of the contraction occurs in the long-axis of the RV from the movement of the tricuspid valve towards RV apex. The RV anterior wall should be examined for bulging and aneurysms, as these are morphologic abnormalities associated with AC. Quantification of RV volumes and ejection fraction should be performed routinely, as these are more reproducible than qualitative estimates and can easily be applied using the current criteria for the purposes of diagnosis.

\section{Computed Tomography of Arrhythmogenic Cardiomyopathy}

Following a similar trajectory to MR imaging, there has been a continuous and accelerated development of CT technology, particularly in the last 10 years focused towards cardiac imaging. Currently available multidetector CT (MDCT) imaging provide excellent spatial resolution, and allow accurate high-resolution assessment of morphological detail of both the cardiac chambers $6,30,31$. The use of a non-ionic contrast agent provides excellent contrast resolution with clear delineation of the ventricular endocardium. Multiple cardiac phases can be extracted, with animated movies of the beating heart made available for visual assessment of global and regional function ${ }^{32,33}$. Quantitative determinations of ventricular mass, right and left ventricular volumes, and global ventricular function can be performed in a variety of cardiac pathologic states.

One of the main advantages of CT over MR imaging is that it is fast, easy to perform, and has more reliable image quality. Although images are acquired only in the axial plane, the acquisition of a 3-dimensional dataset allows reformatting in any desirable plane. For the 
above reasons $\mathrm{CT}$ is a clinically valuable, non-invasive tool for assessment of myocardial pathology.

Computed Tomography imaging has been used to evaluate AC and has the ability to depict the characteristic abnormalities in AC such as abnormal RV morphology and fat infiltration. The ability of conventional CT to detect intramyocardial fat in AC was first reported by Villa et.al, ${ }^{34}$ in a series of seven patients with AC, and subsequently Sotozono et al ${ }^{35}$ provided biopsy confirmation of CT findings. Other investigators have shown the utility of CT in AC including the assessment of LV abnormalities in particular LV fat infiltration. Intramyocardial fat appears as a hypointense signal on CT and this is particularly prominent in the LV wall (Figure 12). Intramyocardial fat is defined based on tissue attenuation values. The attenuation value for epicardial adipose tissue is around - $65 \pm 10$ Hounsfield units (HU), and 5 to $-17 \mathrm{HU}$ for intramyocardial fat which is far less than that of myocardium. Using the above values Tada et al ${ }^{36}$ showed that this was specific for AC as none of the control subjects, and no patient without AC showed any evidence of intramyocardial fat, or any other qualitative features of AC. Further, there is a good correlation between areas of fat detected on CT and abnormal RV endocardial voltage on electroanatomic mapping.

Hamada et al. ${ }^{37}$ imaged four AC patients with RV arrhythmias who had abnormalities on electrocardiography and angiography using EBCT. Quantification of ventricular volumes was performed on cine mode scanning, which showed regional dysfunction and depressed global RV function respectively. Recently a case of AC was evaluated with 64 detector CT and with contrast enhanced volume mode scanning they were able to demonstrate morphologic abnormalities consistent with AC such as RV enlargement, excessive trabeculations, fatty infiltration, and marked RV hypokinesis 38 .

Volumetric assessment of the RV is sub-optimal using CT imaging. Problems that we faced using MDCT include artifacts due to ICD leads, mis-registration of slices, problems with reformatting the short axis data from axial images, all of which undermine the accuracy and reproducibility of the data. Most of the patients who were evaluated using CT imaging at our center had implantable defibrillator hardware which precluded MR imaging. Nevertheless, all the morphologic features are well depicted by CT and chamber dimensions can easily be obtained using the current generation CT imaging.

\section{Role of CT in AC}

Most of centers including ours currently rely on MR imaging instead of CT imaging for evaluating patients with suspected AC mainly because the former is devoid of radiation. The temporal resolution of CT imaging is sub-optimal to allow accurate quantification of volumes. However, most patients who are diagnosed with AC receive implantable defibrillators for prevention of sudden death. In this cohort CT remains the only imaging technique to assess RV structure and function for serial morphologic evaluation. An additional use of CT imaging is to assess the mediastinum for presence of lymphadenopathy, a marker of sarcoidosis, which occasionally mimics $\mathrm{AC}^{39}$. CT imaging also has the ability to assess the lung fields for nodules or granulomas suggestive of sarcoid involvement of the lung. CT is also useful in the occasional patient who has frequent premature beats resulting in arrhythmic artifacts on MR imaging, and also in patients who are claustrophobic.

MDCT radiation can be quite high, exceeding conventional angiography by a factor of 2 when performing retrospective gating 40 . Thus, MDCT may not be optional for "screening of $\mathrm{AC}$ in first degree relatives. Despite the above limitations, CT does provide certain advantages over MR imaging in terms of consistency in image quality, scan time, operator dependency etc. With increase in familiarity of radiologists with the use of helical CT for 
$\mathrm{AC}$ and with the advances in both the temporal and spatial resolution, CT imaging may play an important role both in the diagnosis and in the follow-up of patients with AC.

\section{Acknowledgments}

The authors wish to acknowledge funding from the National Heart, Lung, and Blood Institute (K23HL093350 to HT) and the St. Jude Medical Foundation, Medtronic Inc., and Boston Scientific Corp. The Johns Hopkins ARVD Program is supported by the Bogle Foundation, the Healing Hearts Foundation, the Campanella family, and the Wilmerding Endowments. We are grateful to the ARVD patients and families who have made this work possible.

\section{References}

1. Boxt LM. Radiology of the right ventricle. Radiol Clin North Am. 1999; 37(2):379-400. [PubMed: 10198649]

2. Bluemke DA, Krupinski EA, Ovitt T, Gear K, Unger E, Axel L, Boxt LM, Casolo G, Ferrari VA, Funaki B, Globits S, Higgins CB, Julsrud P, Lipton M, Mawson J, Nygren A, Pennell DJ, Stillman A, White RD, Wichter T, Marcus F. MR Imaging of arrhythmogenic right ventricular cardiomyopathy: morphologic findings and interobserver reliability. Cardiology. 2003; 99(3):153162. [PubMed: 12824723]

3. Araoz PA, Mulvagh SL, Tazelaar HD, Julsrud PR, Breen JF. CT and MR imaging of benign primary cardiac neoplasms with echocardiographic correlation. Radiographics. 2000; 20(5):13031319. [PubMed: 10992020]

4. Higgins CB, Caputo GR. Role of MR imaging in acquired and congenital cardiovascular disease. AJR Am J Roentgenol. 1993; 161(1):13-22. [PubMed: 8517291]

5. Rist C, Johnson TR, Becker CR, Reiser MF, Nikolaou K. New applications for noninvasive cardiac imaging: dual-source computed tomography. Eur Radiol. 2007; 17 Suppl 6:F16-F25. [PubMed: 18376453]

6. Becker CR, Ohnesorge BM, Schoepf UJ, Reiser MF. Current development of cardiac imaging with multidetector-row CT. Eur J Radiol. 2000; 36(2):97-103. [PubMed: 11116173]

7. Simonetti OP, Finn JP, White RD, Laub G, Henry DA. "Black blood" T2-weighted inversionrecovery MR imaging of the heart. Radiology. 1996; 199(1):49-57. [PubMed: 8633172]

8. Bloomer TN, Plein S, Radjenovic A, Higgins DM, Jones TR, Ridgway JP, Sivananthan MU. Cine MRI using steady state free precession in the radial long axis orientation is a fast accurate method for obtaining volumetric data of the left ventricle. J Magn Reson Imaging. 2001; 14(6):685-692. [PubMed: 11747024]

9. Tandri H, Bomma C, Calkins H, Bluemke DA. Magnetic resonance and computed tomography imaging of arrhythmogenic right ventricular dysplasia. J Magn Reson Imaging. 2004; 19(6):848858. [PubMed: 15170788]

10. Tandri H, Calkins H, Nasir K, Bomma C, Castillo E, Rutberg J, Tichnell C, Lima JA, Bluemke DA. Magnetic resonance imaging findings in patients meeting task force criteria for arrhythmogenic right ventricular dysplasia. J Cardiovasc Electrophysiol. 2003; 14(5):476-482. [PubMed: 12776863]

11. Tandri H, Friedrich MG, Calkins H, Bluemke DA. MRI of arrhythmogenic right ventricular cardiomyopathy/dysplasia. J Cardiovasc Magn Reson. 2004; 6(2):557-563. [PubMed: 15137340]

12. Midiri M, Finazzo M, Brancato M, Hoffmann E, Indovina G, Maria MD, Lagalla R. Arrhythmogenic right ventricular dysplasia: MR features. Eur Radiol. 1997; 7(3):307-312. [PubMed: 9087346]

13. Kayser HW, de Roos A, Schalij MJ, Bootsma M, Wellens HJ, Van der Wall EE. Usefulness of magnetic resonance imaging in diagnosis of arrhythmogenic right ventricular dysplasia and agreement with electrocardiographic criteria. Am J Cardiol. 2003; 91(3):365-367. [PubMed: 12565103]

14. van der Wall EE, Kayser HW, Bootsma MM, de Roos A, Schalij MJ. Arrhythmogenic right ventricular dysplasia: MRI findings. Herz. 2000; 25(4):356-364. [PubMed: 10948772] 
15. Castillo E, Tandri H, Rodriguez ER, Nasir K, Rutberg J, Calkins H, Lima JA, Bluemke DA. Arrhythmogenic right ventricular dysplasia: ex vivo and in vivo fat detection with black-blood MR imaging. Radiology. 2004; 232(1):38-48. [PubMed: 15220492]

16. Vikhert AM, Tsiplenkova VG, Cherpachenko NM. Alcoholic cardiomyopathy and sudden cardiac death. J Am Coll Cardiol. 1986; 8 Suppl A(1):3A-11A.

17. Hasumi M, Sekiguchi M, Hiroe M, Kasanuki H, Hirosawa K. Endomyocardial biopsy approach to patients with ventricular tachycardia with special reference to arrhythmogenic right ventricular dysplasia. Jpn Circ J. 1987; 51(2):242-249. [PubMed: 3599366]

18. Macedo R, Prakasa K, Tichnell C, Marcus F, Calkins H, Lima JA, Bluemke DA. Marked lipomatous infiltration of the right ventricle: MRI findings in relation to arrhythmogenic right ventricular dysplasia. AJR Am J Roentgenol. 2007; 188(5):W423-W427. [PubMed: 17449737]

19. Burke AP, Farb A, Tashko G, Virmani R. Arrhythmogenic right ventricular cardiomyopathy and fatty replacement of the right ventricular myocardium: are they different diseases? Circulation. 1998; 97(16):1571-1580. [PubMed: 9593562]

20. Tandri H, Saranathan M, Rodriguez ER, Martinez C, Bomma C, Nasir K, Rosen B, Lima JA, Calkins H, Bluemke DA. Noninvasive detection of myocardial fibrosis in arrhythmogenic right ventricular cardiomyopathy using delayed-enhancement magnetic resonance imaging. J Am Coll Cardiol. 2005; 45(1):98-103. [PubMed: 15629382]

21. Sen-Chowdhry S, Syrris P, Prasad SK, Hughes SE, Merrifield R, Ward D, Pennell DJ, McKenna WJ. Left-dominant arrhythmogenic cardiomyopathy: an under-recognized clinical entity. J Am Coll Cardiol. 2008; 52(25):2175-2187. [PubMed: 19095136]

22. Jain A, Shehata ML, Stuber M, Berkowitz SJ, Calkins H, Lima JA, Bluemke DA, Tandri H. Prevalence of Left Ventricular Regional Dysfunction in Arrhythmogenic Right Ventricular Dysplasia: A Tagged MRI Study. Circ Cardiovasc Imaging.

23. Bloomgarden DC, Fayad ZA, Ferrari VA, Chin B, Sutton MG, Axel L. Global cardiac function using fast breath-hold MRI: validation of new acquisition and analysis techniques. Magn Reson Med. 1997; 37(5):683-692. [PubMed: 9126942]

24. Sakuma H, Fujita N, Foo TK, Caputo GR, Nelson SJ, Hartiala J, Shimakawa A, Higgins CB. Evaluation of left ventricular volume and mass with breath-hold cine MR imaging. Radiology. 1993; 188(2):377-380. [PubMed: 8327681]

25. Marcus FI, McKenna WJ, Sherrill D, Basso C, Bauce B, Bluemke DA, Calkins H, Corrado D, Cox MG, Daubert JP, Fontaine G, Gear K, Hauer R, Nava A, Picard MH, Protonotarios N, Saffitz JE, Sanborn DM, Steinberg JS, Tandri H, Thiene G, Towbin JA, Tsatsopoulou A, Wichter T, Zareba W. Diagnosis of arrhythmogenic right ventricular cardiomyopathy/dysplasia: proposed modification of the Task Force Criteria. Eur Heart J. 31(7):806-814. [PubMed: 20172912]

26. Marcus FI, McKenna WJ, Sherrill D, Basso C, Bauce B, Bluemke DA, Calkins H, Corrado D, Cox MG, Daubert JP, Fontaine G, Gear K, Hauer R, Nava A, Picard MH, Protonotarios N, Saffitz JE, Sanborn DM, Steinberg JS, Tandri H, Thiene G, Towbin JA, Tsatsopoulou A, Wichter T, Zareba W. Diagnosis of arrhythmogenic right ventricular cardiomyopathy/dysplasia: proposed modification of the task force criteria. Circulation. 121(13):1533-1541. [PubMed: 20172911]

27. Dalal D, Tandri H, Judge DP, Amat N, Macedo R, Jain R, Tichnell C, Daly A, James C, Russell SD, Abraham T, Bluemke DA, Calkins H. Morphologic variants of familial arrhythmogenic right ventricular dysplasia/cardiomyopathy a genetics-magnetic resonance imaging correlation study. J Am Coll Cardiol. 2009; 53(15):1289-1299. [PubMed: 19358943]

28. Tandri H, Bluemke DA, Ferrari VA, Bomma C, Nasir K, Rutberg J, Tichnell C, James C, Lima JA, Calkins H. Findings on magnetic resonance imaging of idiopathic right ventricular outflow tachycardia. Am J Cardiol. 2004; 94(11):1441-1445. [PubMed: 15566923]

29. Bomma C, Rutberg J, Tandri H, Nasir K, Roguin A, Tichnell C, Rodriguez R, James C, Kasper E, Spevak P, Bluemke DA, Calkins H. Misdiagnosis of arrhythmogenic right ventricular dysplasia/ cardiomyopathy. J Cardiovasc Electrophysiol. 2004; 15(3):300-306. [PubMed: 15030420]

30. Garcia MJ. Cardiac CT: understanding and adopting a new diagnostic modality. Cardiol Clin. 2009; 27(4):555-562. [PubMed: 19766912] 
31. Sparrow PJ, Merchant N, Provost YL, Doyle DJ, Nguyen ET, Paul NS. CT and MR imaging findings in patients with acquired heart disease at risk for sudden cardiac death. Radiographics. 2009; 29(3):805-823. [PubMed: 19448117]

32. Joemai RM, Geleijns J, Veldkamp WJ, Kroft LJ. Clinical evaluation of 64-slice CT assessment of global left ventricular function using automated cardiac phase selection. Circ J. 2008; 72(4):641646. [PubMed: 18362438]

33. Muhlenbruch G, Das M, Hohl C, Wildberger JE, Rinck D, Flohr TG, Koos R, Knackstedt C, Gunther RW, Mahnken AH. Global left ventricular function in cardiac CT. Evaluation of an automated 3D region-growing segmentation algorithm. Eur Radiol. 2006; 16(5):1117-1123. [PubMed: 16372162]

34. Villa A, Di Guglielmo L, Salerno J, Klercy C, Kluzer A, Codega S. Arrhythmogenic dysplasia of the right ventricle. Evaluation of 7 cases using computerized tomography. Radiol Med. 1988; 75(1-2):28-35. [PubMed: 2964679]

35. Sotozono K, Imahara S, Masuda H, Akashi K, Kamegai M, Miyake F, Murayama M, Sugai J. Detection of fatty tissue in the myocardium by using computerized tomography in a patient with arrhythmogenic right ventricular dysplasia. Heart Vessels Suppl. 1990; 5:59-61. [PubMed: 2093715]

36. Tada H, Shimizu W, Ohe T, Hamada S, Kurita T, Aihara N, Kamakura S, Takamiya M, Shimomura K. Usefulness of electron-beam computed tomography in arrhythmogenic right ventricular dysplasia. Relationship to electrophysiological abnormalities and left ventricular involvement. Circulation. 1996; 94(3):437-444. [PubMed: 8759086]

37. Hamada S, Takamiya M, Ohe T, Ueda H. Arrhythmogenic right ventricular dysplasia: evaluation with electron-beam CT. Radiology. 1993; 187(3):723-727. [PubMed: 8497621]

38. Soh EK, Villines TC, Feuerstein IM. Sixty-four-multislice computed tomography in a patient with arrhythmogenic right ventricular dysplasia. J Cardiovasc Comput Tomogr. 2008; 2(3):191-192. [PubMed: 19083946]

39. Vasaiwala SC, Finn C, Delpriore J, Leya F, Gagermeier J, Akar JG, Santucci P, Dajani K, Bova D, Picken MM, Basso C, Marcus F, Wilber DJ. Prospective study of cardiac sarcoid mimicking arrhythmogenic right ventricular dysplasia. J Cardiovasc Electrophysiol. 2009; 20(5):473-476. [PubMed: 19017339]

40. Hunold P, Vogt FM, Schmermund A, Debatin JF, Kerkhoff G, Budde T, Erbel R, Ewen K, Barkhausen J. Radiation exposure during cardiac CT: effective doses at multi-detector row CT and electron-beam CT. Radiology. 2003; 226(1):145-152. [PubMed: 12511683] 


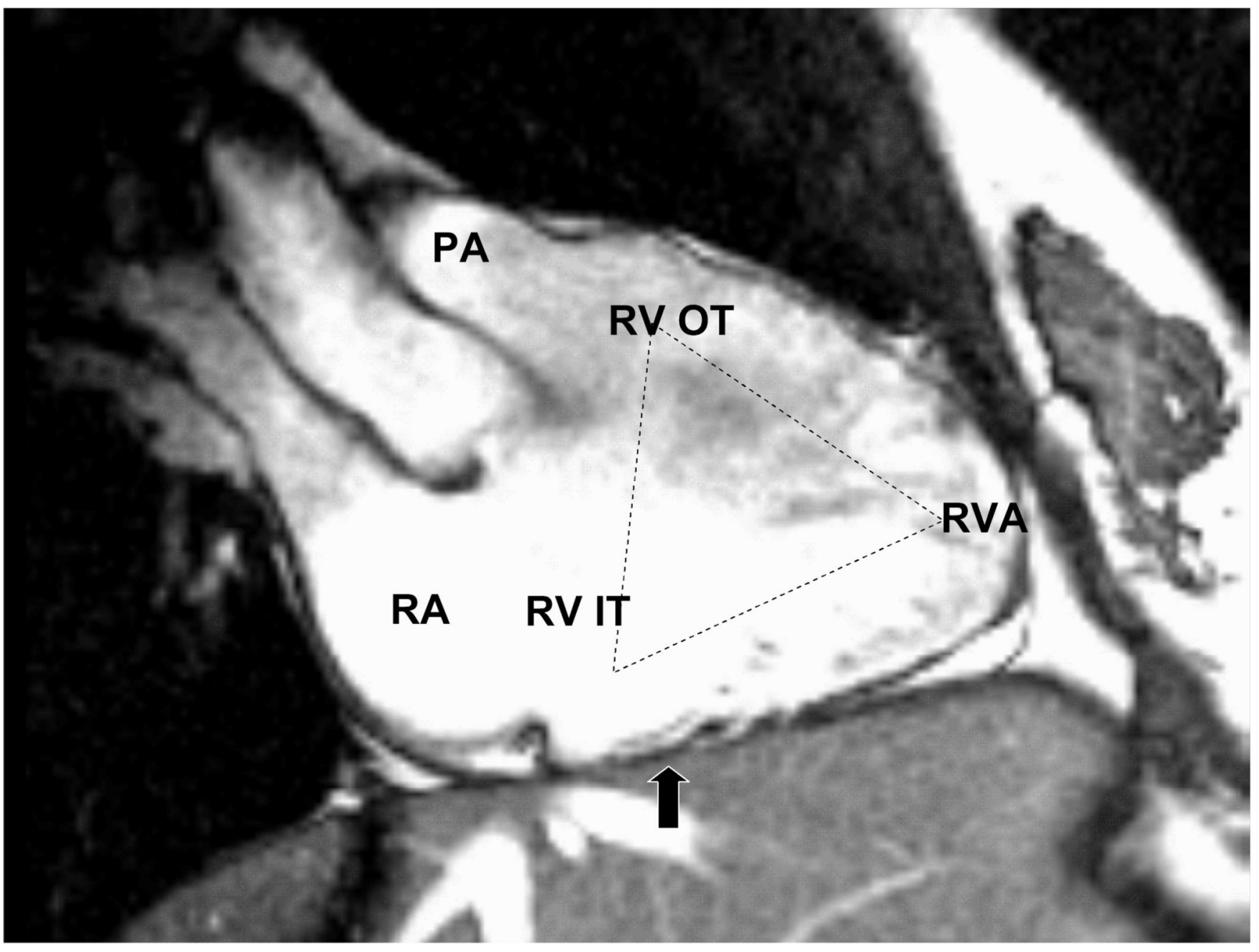

Figure 1. 


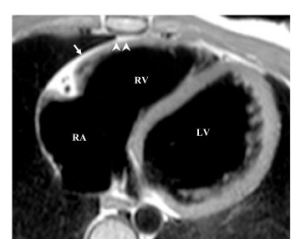

Figure 2. 


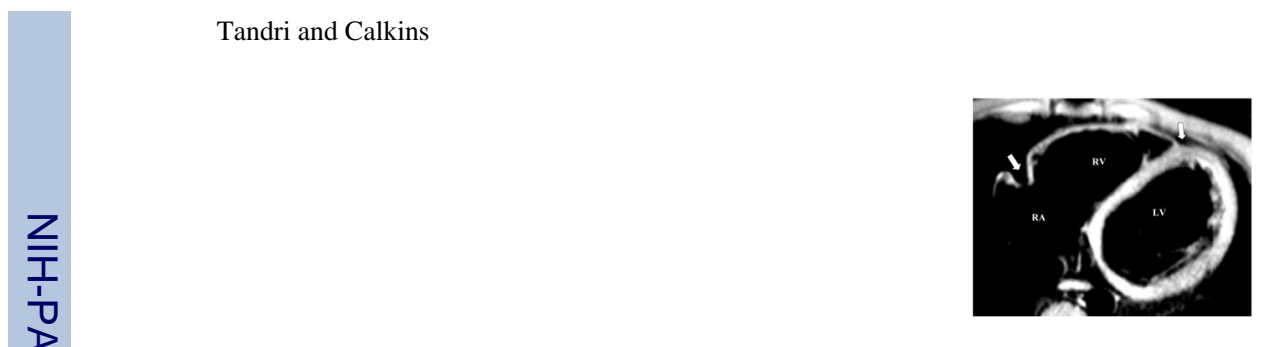

Figure 3 . 


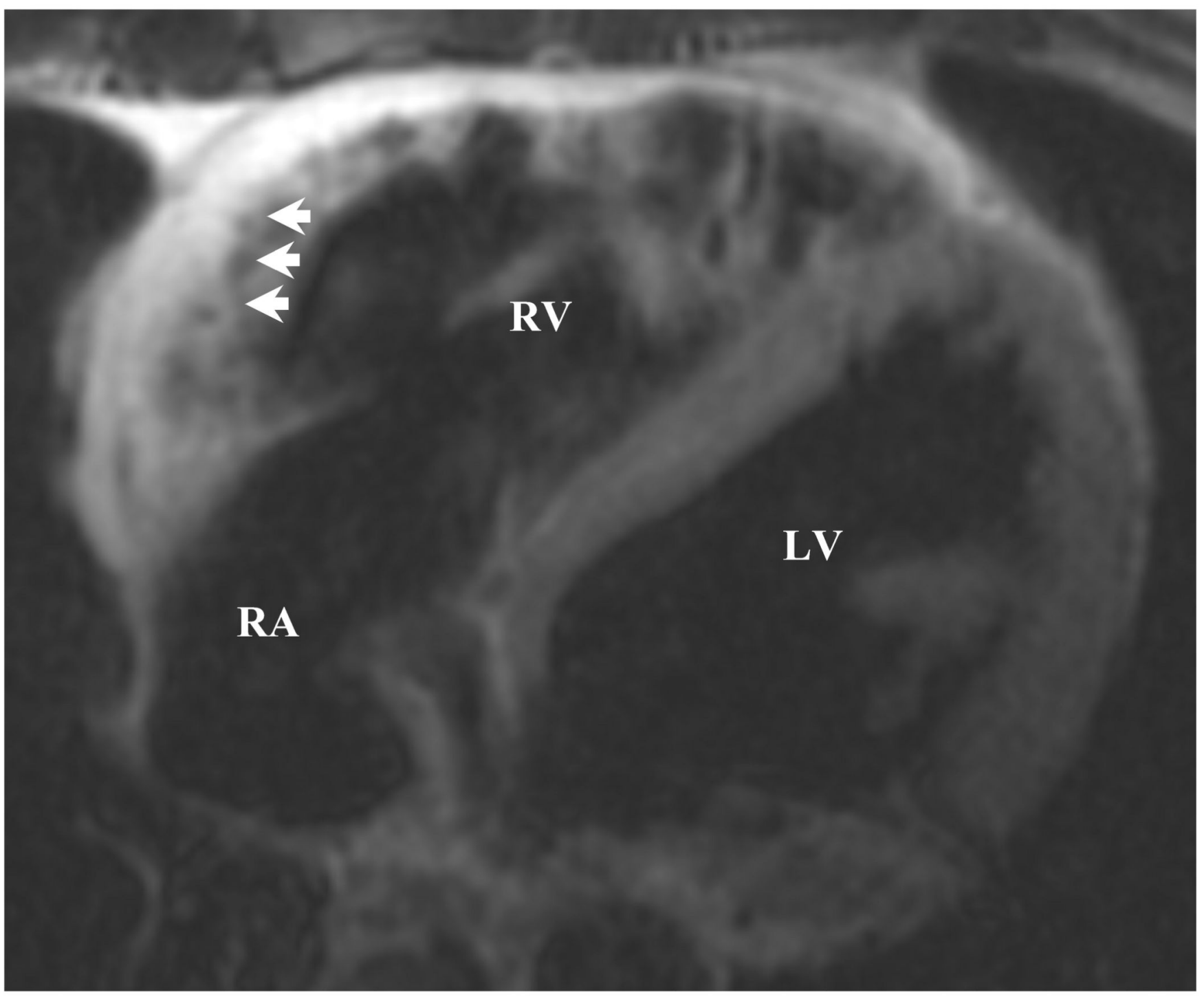




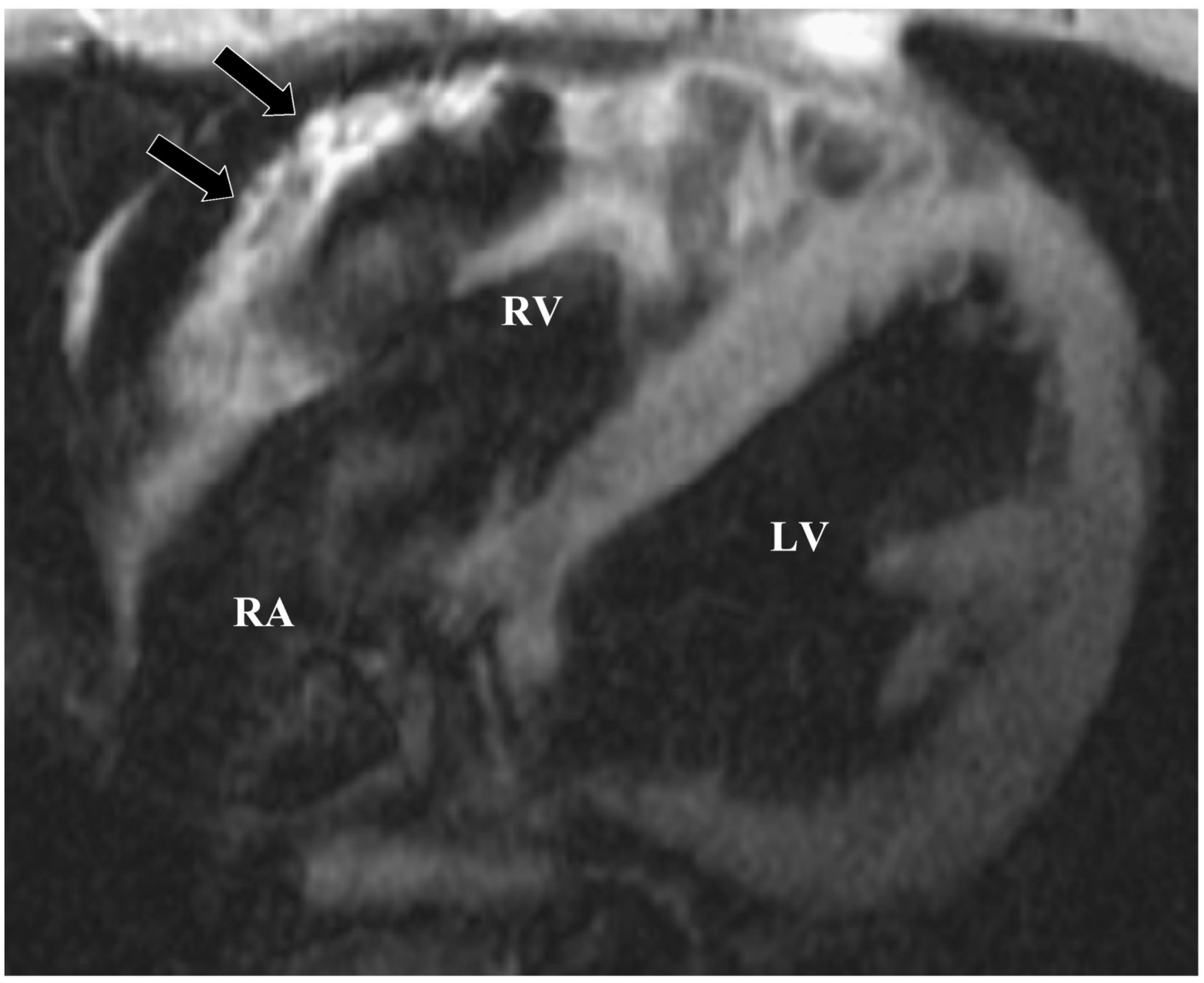

Figure 4. 

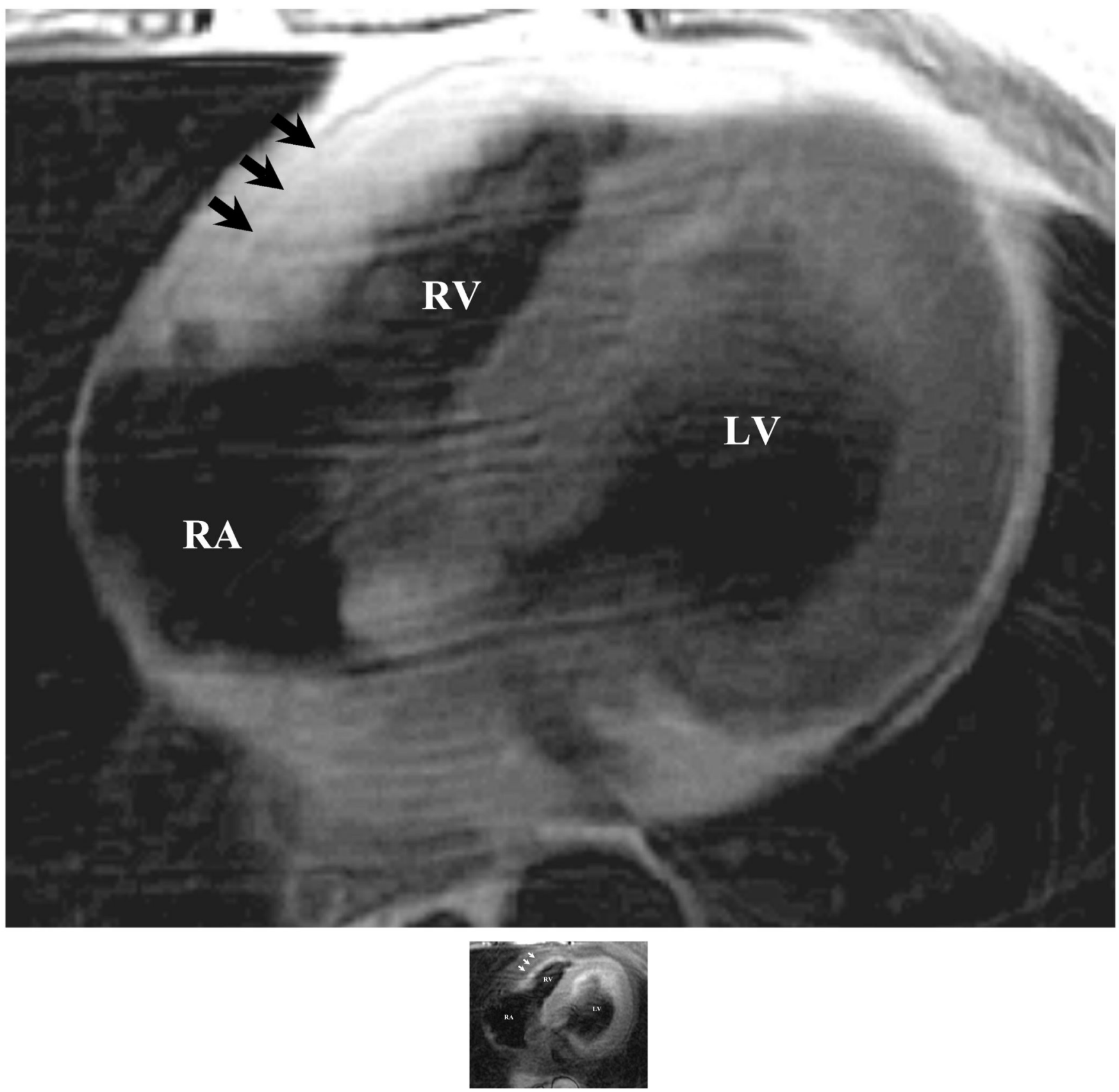

Figure 5. 


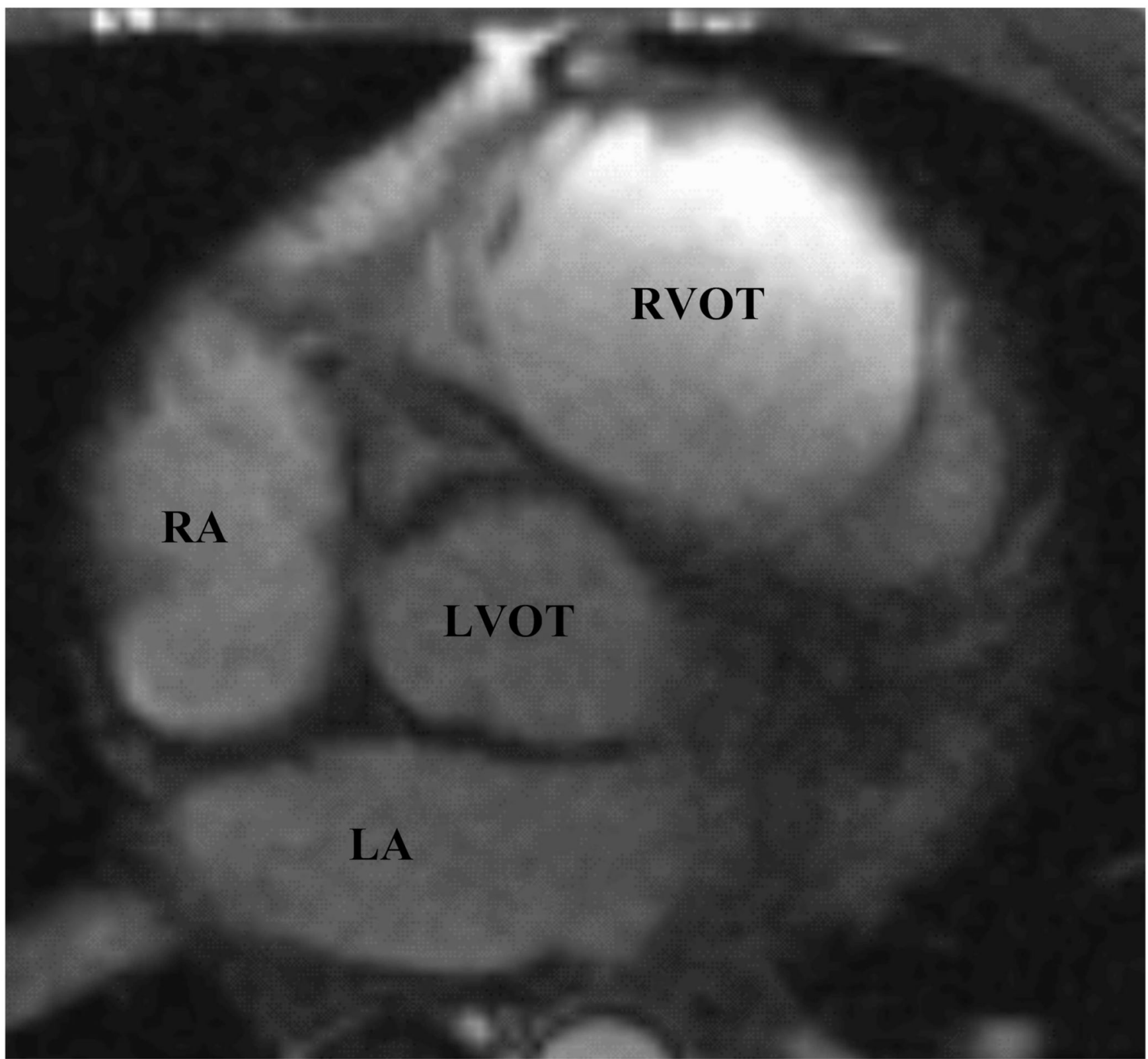

Figure 6. 


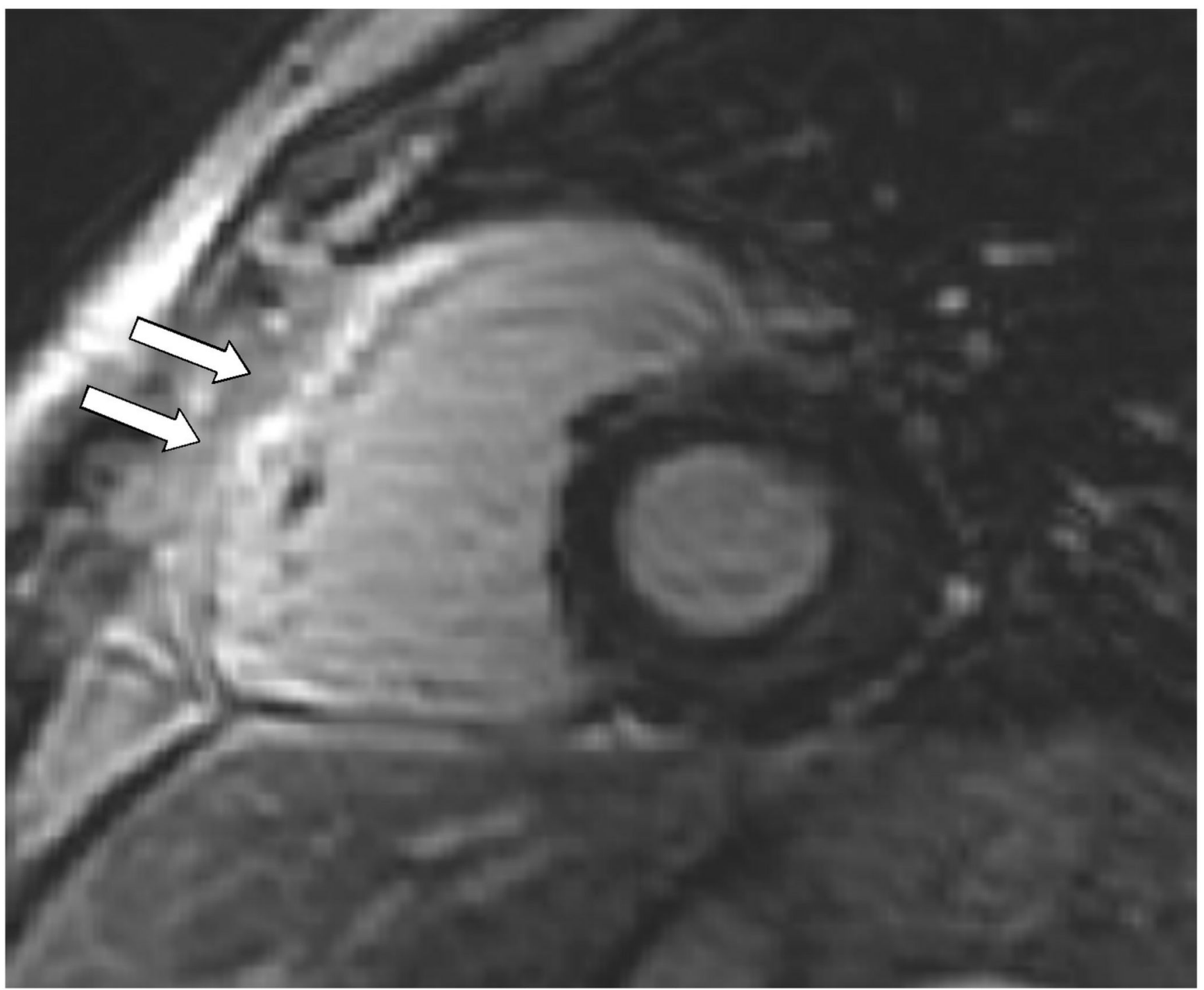

Figure 7. 


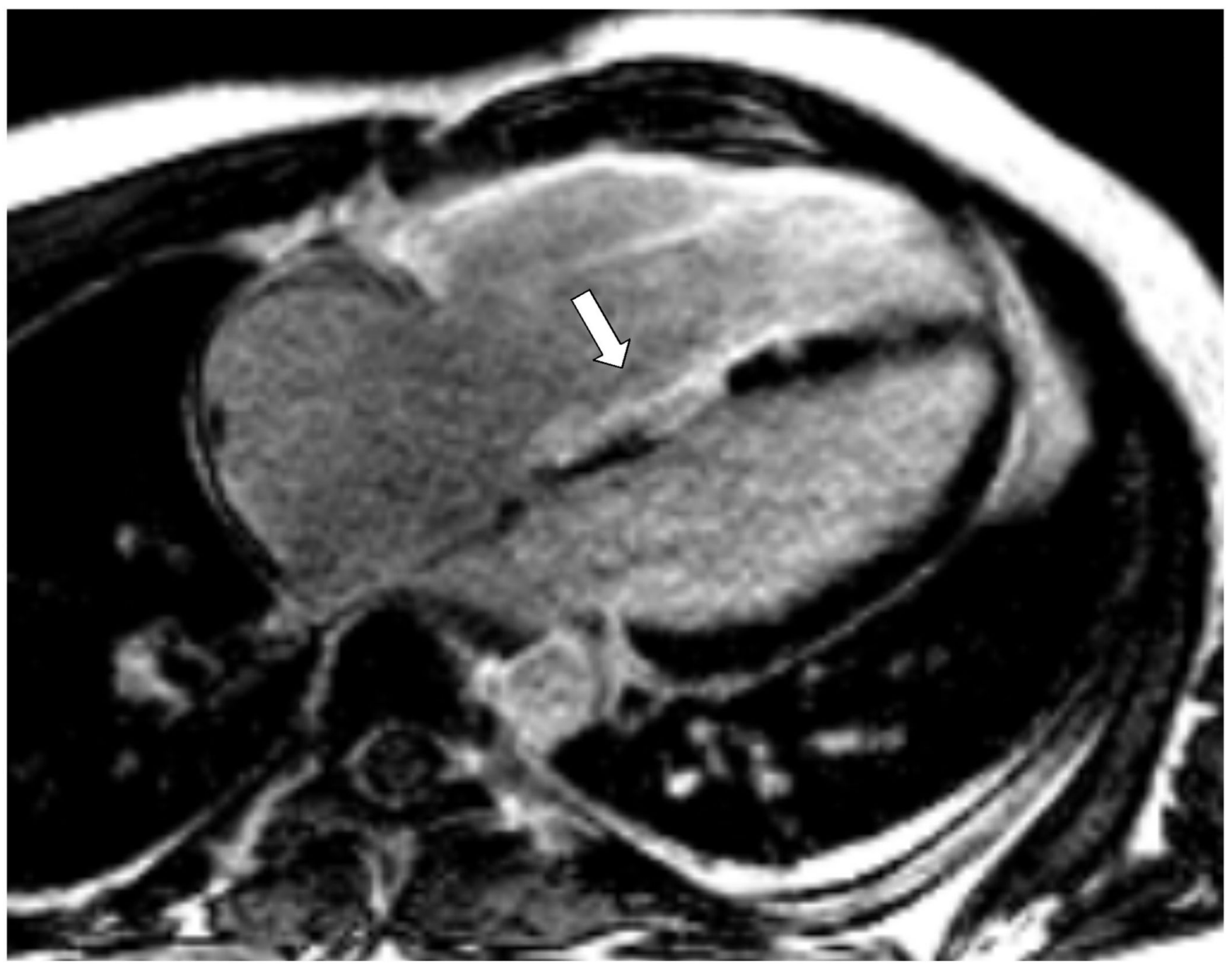

Figure 8. 


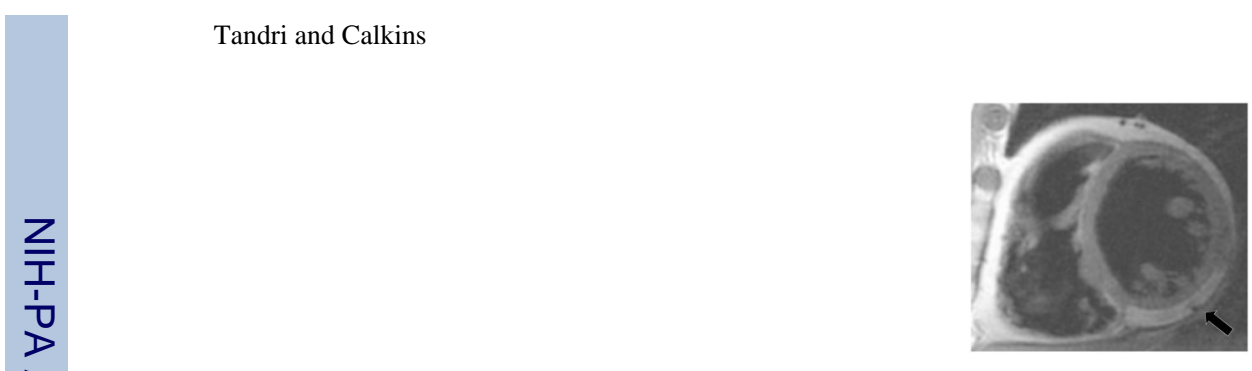

Figure 9. 


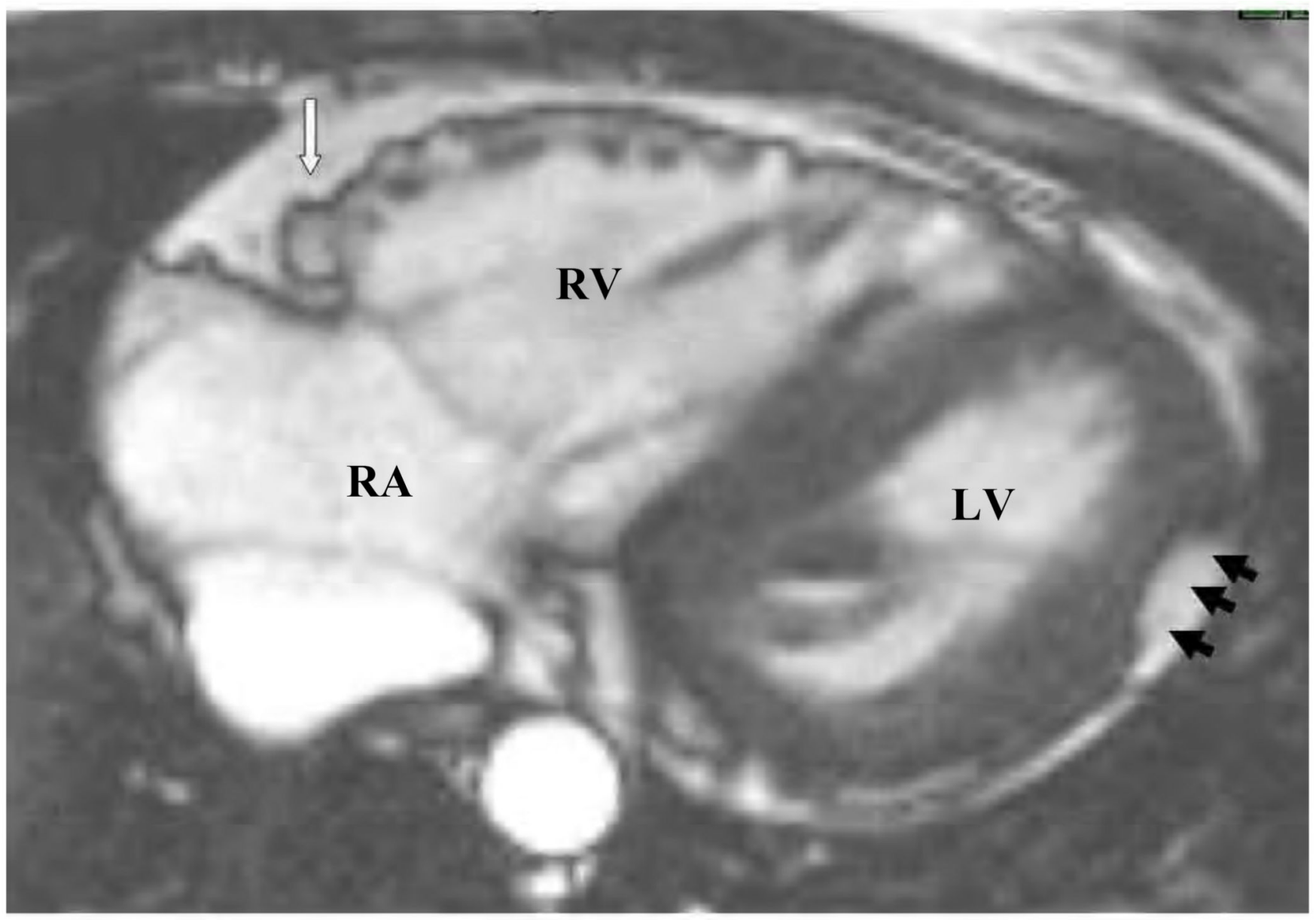

Figure 10. 


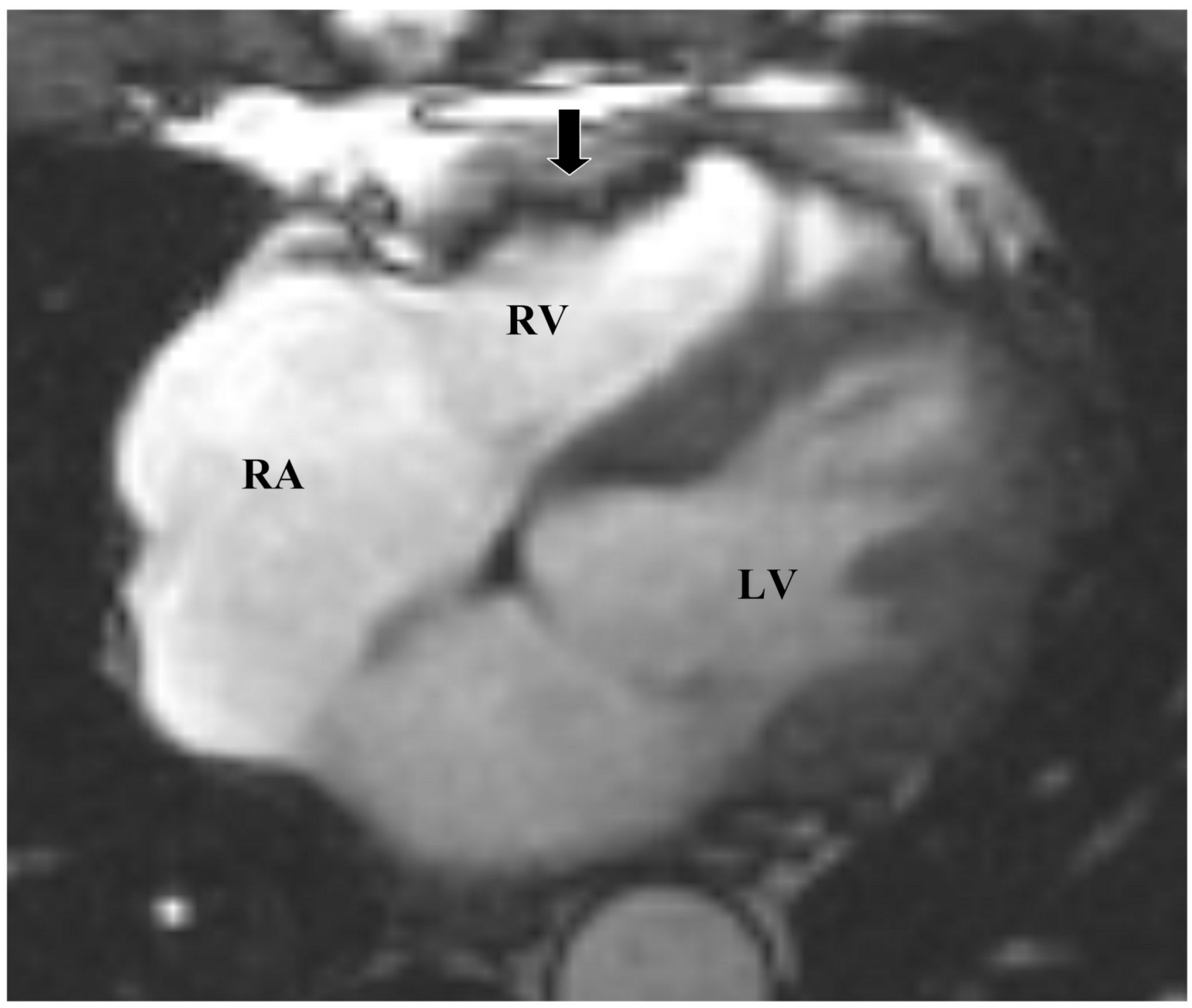

Figure 11. 


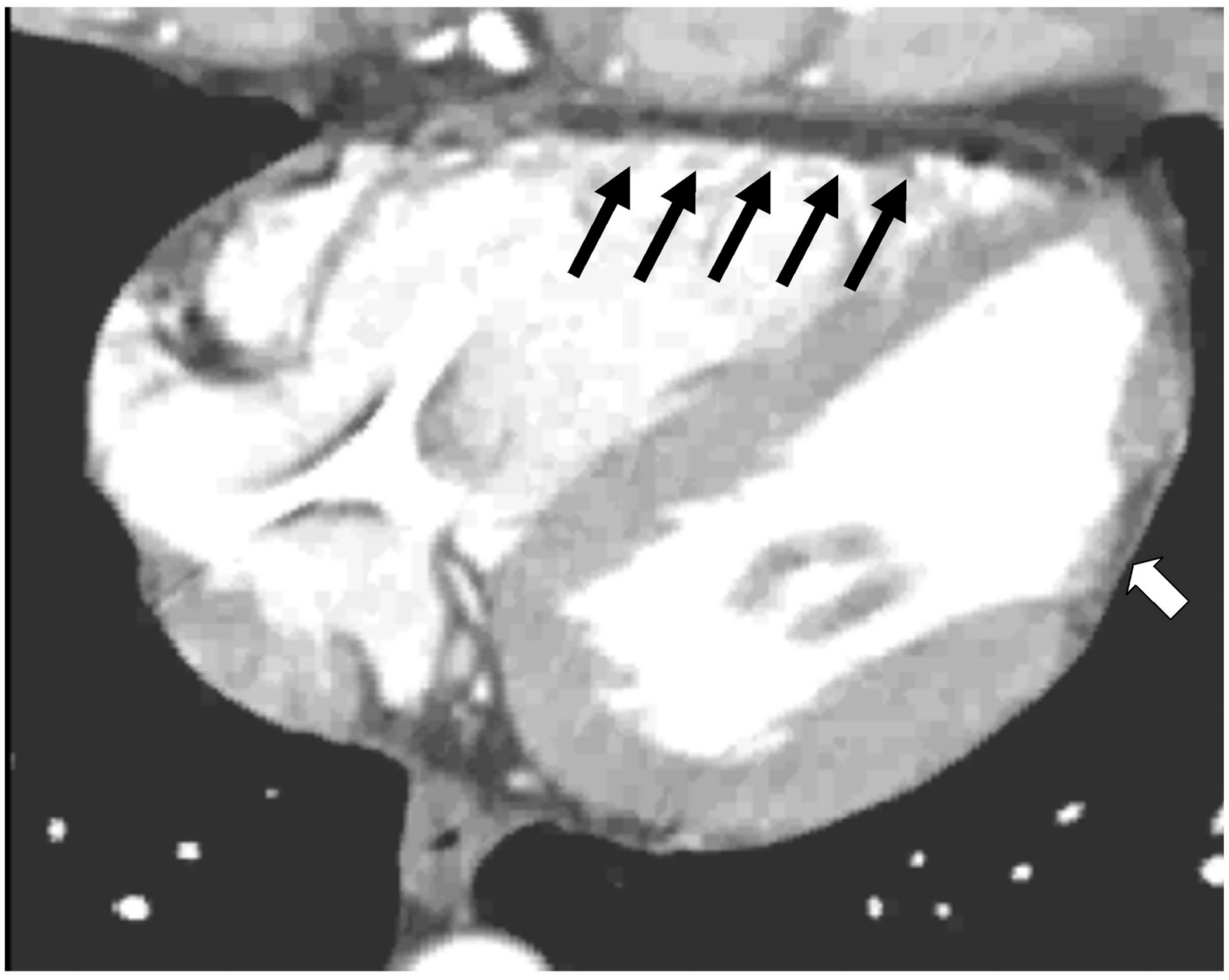

Figure 12. 
Table 1

MR Imaging Protocol For ARVD

\begin{tabular}{lll}
\hline Imaging Sequence & Imaging Plane & Remarks \\
\hline Black Blood Images & Axial & Assess for RV and LV fat infiltration \\
& Short axis & \\
Bright Blood Images & Axial & Assess for RV regional function \\
& Four Chamber & RV size and LV function estimation \\
& Short axis & Optimal for quantification of RV volumes \\
Myocardial Delayed Enhancement & Axial & Assess for fibrosis \\
& Four Chamber & \\
& Short axis & \\
\hline
\end{tabular}

